\title{
Letters
}

Website: bmj.com

Email: letters@bmj.com

\section{Redesigning health care}

\section{Editorial was uncritical regurgitation of NHS Plan}

EDITOR-The BMJ seems to have become an organ of government spin. There is little evidence to justify giving space to Smith's editorial on redesigning health care. ${ }^{1}$ The editorial starts by drawing an analogy with "just in time" manufacturing methods. The closest general practice would come to this is by having open access to investigations and ready access to early outpatient appointments. I am sure that hospital colleagues would love to be in a position to offer this. There is no evidence I am aware of suggesting that delays in primary care are an appreciable factor in treatment time when patients are referred to secondary services.

Smith points out that in the United States "some practices" taking part in the "idealised design" project increased the proportion of their diabetic patients who had their glycated haemoglobin measured from $47 \%$ to $80 \%$. It is laughable to suggest that we need to redesign general practice on such evidence. In my practice, which I am sure is not exceptional, $75 \%$ of diabetic patients have had glycated haemoglobin checked in the past year. As the initial figure from the United States was only $47 \%$, the

\section{Advice to authors}

We prefer to receive all responses electronically, sent directly to our website. Processing your letter will be delayed unless it arrives in an electronic form.

We are now posting all direct submissions to our website within 24 hours of receipt and our intention is to post all other electronic submissions there as well. All responses will be eligible for publication in the paper journal.

Responses should be under 400 words and relate to articles published in the preceding month. They should include $\leqslant 5$ references, in the Vancouver style, including one to the BMJ article to which they relate. We welcome illustrations.

Please supply each author's current appointment and full address, and a phone or fax number or email address for the corresponding author. We ask authors to declare any competing interest. Please send a stamped addressed envelope if you would like to know whether your letter has been accepted or rejected.

Letters will be edited and may be shortened.

bmj.com

letters@bmj.com redesign suggested should be to base the system in the United States on general practice in the United Kingdom.

There is no over-riding case for speeding up appointments in general practice. The American experience of waiting times for general practice appointments may not be readily transferable to the United Kingdom. Seven English practices doesn't seem a firm foundation to justify redesigning appointments. Prebooked appointments can be more convenient for many patients and do not just represent a backlog of work. The suggestion of Mark Murray from the American projectthat we should match capacity to demand and try to do more in each consultation ${ }^{1}$-was probably closer to the reason why any system would cope with more work.

Other measures to reduce visits to general practitioners included using the telephone. This is probably not a new idea to many general practitioners in the United Kingdom: many are likely to be doing this already. The availability of appointments on the day is not likely to reduce overall demand on general practitioners: in my practice patients have not turned up for appointments booked as urgent on the same day.

Paul Meadows general practice principal Priory Surgery, Bristol BS4 2OJ pmbr34891@blueyonder.co.uk

1 Smith J. Redesigning health care. BMJ 2001;322:1257-8. (26 May.)

\section{Steady state demand is myth}

EDITOR-When the MGF motor car came on to the market in the mid-1990s one of the motoring journalists warned that because the market for soft top cars was only $2.5 \%$ it would not sell. Now, less than 10 years later, sales of soft top cars make up $15 \%$ of all new car sales.

What, readers may ask, has this to do with Smith's editorial?' A market changes not just because of demands put on it but because of what it offers. Everybody knows this-except, apparently, our own boffins. The steady state so fundamental to the access plan of "doing today's work tomorrow" is a myth for three reasons.

Firstly, it does not allow for leakage of demand elsewhere in the system. Patients may well be seeing health visitors/casualty doctors/osteopaths or calling NHS Direct rather than seeing their own general practitioner because of the wait. Removing the wait will see demand rise; how else do fast food chains work?
Secondly, it does not allow for changes in doctors' working practice. A doctor might be content to see a patient only once a year as a compromise between demands on him or her and the care the patient needs. Any change in that doctor's perceived level of demand will shift the consultation frequency, either increasing the workload or reducing patient care.

Thirdly, there is the United Kingdom context in all this. Fewer general practitioners than the European average doing twice as much work with $5 \%$ less of the total health budget must mean that doctors in the United Kingdom start from a different position than do doctors in the United States or the rest of Europe.

Smith talks of leadership. Leadership is possible only when you believe in not only the mission but also the method. Many of us jobbing general practitioners are not sceptics at heart; we just do not believe the method.

James Cave general practitioner

Downland Practice, Chieveley, Newbury, Berkshire RG20 8TZ

jamescave@btinternet.com

1 Smith J. Redesigning health care. BMJ 2001;322:1257-8. (26 May.)

\section{Practices in UK are working harder, not more efficiently}

EDITOR-While participating in the United Kingdom Primary Healthcare Collaborative my practice has seen an improvement in patient access. ${ }^{1}$ This has been achieved by increasing the number of appointments. Information about consultation rates has not been collected by the collaborative project, and to display information about improved access in the absence of this information is worthless.

At the last national meeting of the Primary Care Collaborative in Leicester it was evident that many of the practices were simply working harder, with longer surgery times, and in a way that would be difficult to sustain in the long term.

Iain B Craighead general practice principal Fern Hill Medical Practice, Faringdon, Oxfordshire SN7 7EZ

IainCraighead@aol.com

1 Smith J. Redesigning health care. BMJ 2001:322:1257-8. (26 May.)

\section{Terminology used in article on cloning was incorrect}

EDITOR-The myth that stem cells developed by cloning will be genetically similar to the adult needs to be exposed. Scientifically, the statements in the box in Mayor's news 
article are wrong. ${ }^{.}$The Donaldson report (page 23, para 2.28) states "animals born from cell nuclear replacement are not exactly identical to the animal cell whose cell nucleus was used in the process. They inherit mitochondrial DNA (contained in the outer layer of the egg) from the (enucleated) egg used in the nuclear replacement process. The implications of this for the compatibility of tissues derived from embryos created by cell nuclear replacement (cloning) is not known."

For this reason, stem cells created by therapeutic cloning cannot be genetically identical because the embryonic stem cells will contain the mitochondrial genes in the cytoplasm of the enucleated female egg. Cloning causes serious biochemical and structural problems in animals. ${ }^{3}$ Mitochondrial damage would explain the biochemical problems. Four essential biochemical pathways-the citric acid cycle, respiratory chain, oxidative phosphorylation, and fatty acid oxidation-occur in the mitochondrial organelles. Damage to any of these pathways would cause serious biochemical problems.

The age at which mitochondrial illnesses present is affected by intrinsic as well as extrinsic factors. ${ }^{4}$ Inherited mitochondrial disease can cause blindness, defective muscles (including cardiac muscle), maturity onset diabetes, and deafness. Furthermore, mitochondrial and cell surface receptors mediate the two main pathways of apoptosis. ${ }^{5}$ And apoptosis has a role in neurodegeneration as well as in cancer.

As far as mitochondrial diseases are concerned, a healthy newborn child does not imply a healthy adult. Many years will have to pass before we can be absolutely certain that techniques currently being used by reproductive scientists for in vitro fertilisation are not causing mitochondrial damage. What is certain, however, is that cloning causes serious biochemical abnormalities in newborn cows. ${ }^{2}$

Peter Millard emeritus professor of geriatrics, St George's Hospital Medical School 12 Cornwall Road, Cheam, Sutton, Surrey SM2 6DR peter.millard@tinyworld.co.uk

1 Mayor S. Ban on human reproductive cloning demanded. BMJ 2001;322:1366. (30 June.)

2 Donaldson L. Stem cell research:medical progress with respomsibility. London: Department of Health, 2000.

3 Cohen P. Concar D. The awful truth: why would anyone in their rigt mind want to cwu the their right mind want to clone a baby when animal cloning can go disastrously wrong? New Scientist 2001 May19:14-5. Turker M. Premature aging. In: Birren J, ed. Encyclopedia of gerontology. Vol 2. San Diego: Academic Press, 1996:341-54. goes wrong in cancer. BMJ 2001;322:1538-9. (23 June.)

\section{Blood pressure measurement}

\section{$\mathrm{ABC}$ shows absence of evidence in measuring blood pressure during pregnancy}

EDITOR-In the short ABC on blood pressure measurement Beevers et al made several references to problems with measurement in pregnancy that have been

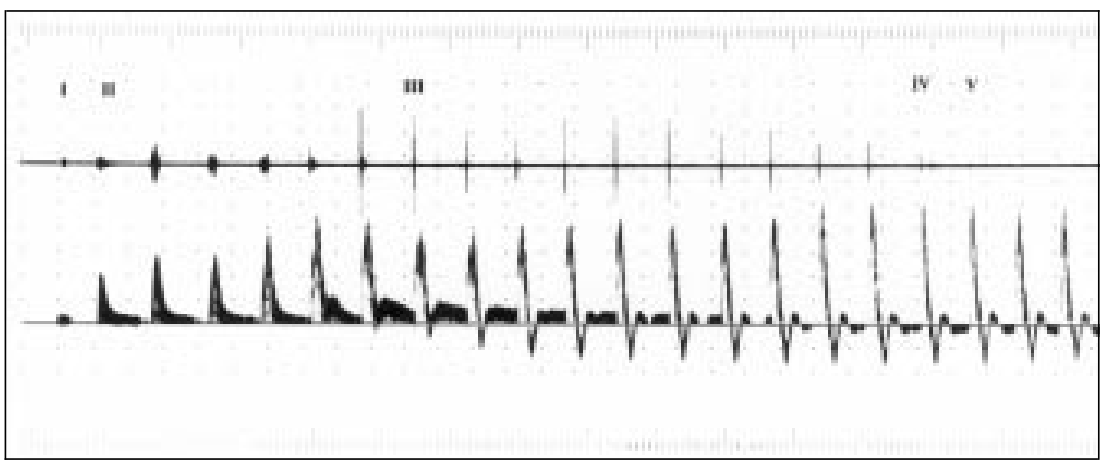

Sequence of vascular sounds in normotensive pregnancy. Vascular sounds were recorded with microphone over brachial artery (Toshiba HSM-05B), with concomitant Doppler recording of brachial artery waveform (Toshiba PLF703ST)

discussed for many years without satisfactory resolution. ${ }^{1}$ There are four main points.

(1) Interestingly, the vascular sounds that are caused by vibration of the vessel wall are clearly modulated by consistent changes in patterns of flow in the brachial artery in pregnancy (figure). ${ }^{2}$

(2) As the authors indicate, automated oscillometric devices may be inaccurate; they systematically under-record K1 (phase I; onset of sounds) and K4 (phase IV; muffling of sounds) in severe pre-eclampsia by up to $40 \mathrm{~mm} \mathrm{Hg.}{ }^{3}$ Other circulatory conditions characterised by reduced compliance may be susceptible to similar discordances.

(3) K5 (phase V; disappearance of sounds) may be the "most accurate measurement of diastolic blood pressure in pregnancy," but academic precision may be less relevant than pragmatic thresholds in preventing the consequences of severe pre-eclampsia and eclampsia. Measurements of K1 and $\mathrm{K} 4$ of 140/90 $\mathrm{mm} \mathrm{Hg}$ and $160 / 110 \mathrm{~mm} \mathrm{Hg}$ may be difficult to improve on. Perhaps the authors have alternative techniques and thresholds in mind?

(4) In the British eclampsia survey 294 out of 383 patients with eclampsia had the characteristic symptoms associated with severe hypertension, although only 70 had a diastolic blood pressure $>120 \mathrm{~mm} \mathrm{Hg}$ before the seizure. ${ }^{4}$ The authors who reported the survey suggested that these observations might be accounted for by an increase in "normotensive eclampsia." An alternative explanation might be that in labour wards in the United Kingdom blood pressure is usually measured with automated oscillometric devices, which consistently under-record when compared with K1 and $\mathrm{K} 4$, so that women and their babies continue to be exposed to serious morbidity.

It is always helpful for obstetricians and gynaecologists to have their practices carefully scrutinised, since so much is not underpinned by rigorous evidence. The $\mathrm{ABC}$ emphasises the absence of such evidence. If European Union directives advise mercury to be withdrawn from the workplace I would be grateful to know how to measure blood pressure in severe pre-eclampsia so as to prevent the potentially serious consequences of this syndrome.
Martin Quinn locum consultant in obstetrics and gynaecology

Hinchingbrooke Hospital, Huntingdon PE29 6NT martin.quinn@hbhc-tr.anglox.nhs.uk

1 Beevers G, Lip GYH, O'Brien E. ABC of hypertension: Blood pressure measurement. BMJ 2001;322:981-5. (21 April.)

2 Quinn MJ. Korotkoff's sounds in pregnancy. Ultrasound in Obstetrics and Gynaecology 1995;6:58-61.

3 Quinn MJ. Automated blood pressure measurement devices: a potential source of morbidity in severe preeclampsia? Am J Obstet Gynecol 1994;170:1303-7.

4 Douglas KA, Redman CW. Eclampsia in the United Kingdom. BMJ 1994;309:1395-400.

\section{Single measurements would not} withstand 21 st century peer review

EDITOR-There cannot be a doctor who does not know how to perform the very basic technique of blood pressure monitoring, so the reason for publishing a detailed review of the factors involved must be to improve the way routine measurements are obtained. ${ }^{1}$ The recommendations are therefore disappointing-specifically, the fact that the authors are prepared to advocate the use of a single reading unless there is a specific distraction.

This simply reiterates an unvalidated tradition; it would not withstand peer review in any reputable journal if newly invented. The Reverend William Hales, in the 18th century (long before ambulatory measurements), observed that minute to minute arterial pressure is remarkably variable. A single reading, therefore, means as much as a random depth measurement of a river at an unspecified time.

Worse, with an inflatable cuff the first reading is particularly unreliable, since it may simply serve to bed the cuff into position: it should be routinely discarded, rather than being the only reading. A reproducible value requires three to five subsequent readings. ${ }^{23}$ Because time of day and whether the day is a working day or a less stressful day also affect blood pressure, these factors should be held constant for an individual patient if readings taken on consecutive occasions months apart are to have any likelihood of sensitively detecting important changes. These will otherwise be masked by avoidable random variation; failure to detect upward trends until they stand out from the unnecessary noise imposes a potentially damaging delay.

The extra care entailed by obtaining proper measurements is trivial beside the cost of hypertensive damage and diabetic 
nephropathy. The clinical consequences of hypertension are so important that the fundamental measurement deserves to be taken with proper regard to precision, and with the same care that is now taught to veterinary surgeons. ${ }^{4}$

A R Michell professor of comparative medicine St Bartholomew's Hospital, London EC1A 7BE bobmichell@hotmail.com

1 Beevers G, Lip GYH, O'Brien E. ABC of hypertension: Blood pressure measurement. BMJ 2001;322:1043-7. (28 April.)

2 Norm R, Myers M, McKay D. Is usual measurement of blood pressure meaningful ? Blood Pressure Monitoring 1999;4:71-6.

3 Michell A. Routine blood pressure measurement: application of the standard canine technique to a human. Blood Pressure Monitoring 1996;1:385-7.

4 Bodey AR, Michell AR, Baree KC, Buranakurl C. Comparison of direct and indirect (oscillometric) measurements of arterial blood pressure in dogs. Res Vet Sci 1996;61:17-21.

\section{Authors' reply}

EdIToR-We agree with Quinn that several issues in relation to blood pressure measurement in pregnancy "have been discussed for many years without satisfactory resolution" and that as a consequence our review may reflect the absence of such evidence. We attempted, nevertheless, to make the most of what evidence is available and, by doing so, to help clinical practice. ${ }^{1}$

The general consensus from obstetricians is that $\mathrm{K} 5$ (disappearance of sounds) is the best measure of diastolic pressure in pregnancy, although we acknowledge that much of the evidence for outcome in pregnancy derives from $\mathrm{K} 4$ (muffling). ${ }^{2} \mathrm{We}$ would urge our obstetric colleagues to provide the evidence on which to base future management decisions.

With regard to automated alternatives to the mercury sphygmomanometer, we would agree with Quinn's contention that these devices are not always proved to be accurate in pregnancy. ${ }^{3}$ As the British Hypertension Society's protocol recommends, all blood pressure measuring devices should be validated in special populations, such as pregnant women. ${ }^{4}$

Had Michell read our articles he would have noted our constant emphasis on the need to obtain multiple (preferably ambulatory) measurements before making any clinical decisions. The two words that he selectively quotes were used in the context of advocating one careful measurement rather than numerous careless hurried measurements. If he had read the next sentence he would not need to have repeated what we had already stated unequivocally: "As a result of the variability of measurements of casual blood pressure decisions based on single measurements will result in erroneous diagnosis and inappropriate management. Reliability of measurements is improved if repeated measurements are made."

Eoin O'Brien professor of cardiovascular medicine Blood Pressure Unit, Beaumont Hospital, PO Box 1297, Dublin 9, Republic of Ireland eobrien@iol.ie

Gregory Y H Lip professor of cardiovascular medicine D Gareth Beevers professor of medicine

University Department of Medicine, City Hospital, Birmingham B18 7QH
1 Beevers G, Lip GYH, O’Brien E. ABC of hypertension Sphygmomanometry: factors common to all techniques. BMJ 2001;322:981-5. (21 April.)

2 De Swiet M. K5 rather than K4 for diastolic blood pressure measurement in pregnancy. Hypertension in Pregnano 1999;18:3-5.

3 O'Brien E, Waeber B, Parati G, Staessen J, Myers MG on behalf of the European Society of Hypertension Working behalf of the Euper Group on Blood Pressure Monitoring. Blood pressure measuring devices: recommendations of the Europea -6. (3 March.)

4 O'Brien E, Petrie J, Littler WA, de Swiet M, Padfield PL, Altman D, et al. The British Hypertension Society protocol for the evaluation of blood pressure measuring devices. J Hypertens 1993;11(suppl 2):S43-63.

\section{Doctors who cannot calibrate sphygmomanometers should stop taking blood pressures}

EDITOR-Professionals often use specialist equipment to diagnose or remedy a problem. If they use equipment of unknown reliability they are acting unprofessionally and failing in their duty of care ${ }^{1}$; their action is also reckless and unethical. Furthermore, it could result in a claim for negligence if a patient thinks that harm resulted from the use of unreliable equipment.

To ensure that they are acting professionally, safely, and ethically, professionals must immediately stop using equipment of uncertain reliability and arrange for the regular calibration and maintenance of all equipment. This is generally best done by formally delegating responsibility to a suitably qualified person or organisation.

In the $\mathrm{ABC}$ of hypertension the authors emphasise the professional duty to ensure that when blood pressure is measured the readings obtained are accurate. ${ }^{2}$ They also state that the reliability of mercury sphygmomanometers cannot be taken for granted $^{3}$ and that some sphygmomanometers are notoriously inaccurate. ${ }^{2}$

The authors do not, however, give clear advice to stop using sphygmomanometers of unknown reliability. We find this surprising. The principle is well established in health care. If we are unsure about the integrity of the cold chain we throw the vaccine away; if an autoclave has not undergone routine servicing we do not use it. What is so different about sphygmomanometers? Is their use exempt from this important quality assurance principle? We think not.

In these litigious times things are about to change. It can only be a matter of time before a patient seeks damages on the basis that he or she suffered harm because the doctor used an unreliable sphygmomanometer. Without convincing evidence that the doctor's sphygmomanometer was reliable such a claim will be hard to defend. The fact that it is common for doctors to use uncalibrated equipment can no longer be relied on to provide a successful "Bolam" defence. Judges have long ruled that medical actions and treatments must be logical. ${ }^{1}$ Can readers justify to their patients or argue before a judge that use of an uncalibrated sphygmomanometer is logical?

Tom Marshall lecturer in public health Andrew Rouse senior lecturer in public health University of Birmingham, Department of Public Health and Epidemiology, Birmingham B15 2TT
1 Bolitho $v$ City and Hackney Health Authority www.dentolegal.com/page4.html (accessed 7 June 2001) 2 O'Brien E, Beevers G, Lip GYH. ABC of hypertension: Blood pressure measurement. BMJ 2001;322:1167-70. (12 May.)

3 Beevers G, Lip GYH, O’Brien E. ABC of hypertension: Blood pressure measurement. BMJ 2001;322:1043-7. (28 April.)

4 Rouse A, Marshall T. The extent and implications of sphygmomanometer calibration error in primary care. JHum Hypertens (in press).

\section{Reference limits for haemoglobin and ferritin}

\section{If it's not broken, don't fix it}

EDiToR-Rushton et al suggest that reference ranges for men should be used to assess iron status in women of childbearing age. ${ }^{1}$ They do, however, make some incorrect assumptions and do not consider the practical implications of such a change.

Women must have sufficient iron stores to prevent iron deficiency from menstrual blood loss or pregnancy. However, one in 150 people in the United Kingdom are homozygous for the C282Y mutation of the HFE gene, which is associated with haemochromatosis. ${ }^{2}$ Although the clinical penetrance of this genotype is low, widespread measures to increase the intake of iron in younger women will also increase the intake of men and postmenopausal women. It is therefore important that any changes in lower limits of indices of iron status are firmly supported by clinical and experimental evidence.

Rushton et al are incorrect in assuming that different lower limits for ferritin are used for detecting iron deficiency in young men and women. Although reference ranges $(95 \%)$ in healthy young adults differ-for example, 35-220 $\mu \mathrm{g} / \mathrm{l}$ for men and 9-136 $\mu \mathrm{g} / \mathrm{l}$ for women ${ }^{2}$-the limit for iron deficiency used by clinicians is around $15 \mu \mathrm{g} / \mathrm{l}$ for both men and women, a value originally established by determining the highest value found in patients with iron deficiency anaemia. ${ }^{3}$

The national dietary and nutritional survey reported a median value for haemoglobin concentration in British women of childbearing age of $132 \mathrm{~g} / \mathrm{l}$. Increasing the lower cut-off point to $130 \mathrm{~g} / \mathrm{l}$, as used for men, would therefore define half the premenopausal adult female population of the United Kingdom as anaemic. Zhu and Haas found that in women with serum concentrations of ferritin $<16 \mu \mathrm{g} / \mathrm{l}$ and haemoglobin $>120 \mathrm{~g} / \mathrm{l}$, iron supplementation increased serum concentrations of ferritin but not haemoglobin. ${ }^{4}$ We also have to ask how the iron intake of all these women would be increased. A recent dietary intervention study showed that highly motivated people with mild iron deficiency can improve iron status through diet but that supplements are a more practical option. ${ }^{5}$ Supplements do, however, produce unpleasant side effects in a notable proportion of individuals, and any programme entailing the use of supplements is likely to have a 
detrimental effect on the wellbeing of a notable number of women.

We believe that there is no evidence to support reclassification of haemoglobin and serum concentrations of ferritin in women to normal values for men. Furthermore, we are unable to see how such a move could result in a positive outcome for women's health and welfare with no adverse effects.

Anne-Louise M Heath postdoctoral fellow

annelouise.heath@bbsrc.ac.uk

Susan Fairweather-Tait head of division

Nutrition and Consumer Science Division, Institute of Food Research, Norwich Research Park, Colney, Norwich, NR4 7UA

Mark Worwood professor

Department of Haematology, University of Wales College of Medicine, Cardiff, CF14 4XN

1 Rushton DH, Dover R, Sainsbury AW, Norris MJ, Gilkes $\mathrm{JJH}$, Ramsay ID. Why should women have lower reference limits for haemoglobin and ferritin concentrations than men? BMJ 2001;322:1355-7. (2 June.)

2 Jackson HA, Carter K, Darke C, Guttridge MG, Ravine D, Hutton RD, et al. HFE mutations, iron deficiency and overload in 10,500 blood donors. Br J Haematol 2001;114:474 84.

3 Worwood M. Serum ferritin. In: Jacobs A, Worwood M, eds Iron in biochemistry and medicine, II. London: Academic Press, 1980.

4 Zhu YI, Haas JD. Response of serum transferrin receptor to iron supplementation in iron-depleted, nonanemic to iron supplementation in iron-dep.
women. Am J Clin Nutr 1998;67:271-5.

5 Heath A-LM, Skeaff CM, O'Brien SM, Williams SM, Gibson RS. Can dietary treatment of pre-anemic iron deficiency improve iron status? J Am Coll Nutr 2001 (in press).

\section{Differences in haemoglobin concentrations reflect physiological differences}

EDITOR-Rushton et al argued that a high prevalence of iron deficiency among women has resulted in the use of haemoglobin reference ranges that are lower than ideal, and that male reference ranges should be used when assessing the iron status of women.

We have used two independent sources of data to show that sex differences in haemoglobin concentrations reflect real physiological differences rather than the prevalence of iron deficiency. We have used specific exclusion criteria (ferritin, age, pregnancy) to ensure that the two groups were comparable and iron replete. The first data set, extracted from our community laboratory database, consists of 612 men and 1327 women aged 20-45 years, all of whom have a serum ferritin value within the narrow range of 80-100 $\mu \mathrm{g} / 1$ (indicating adequate iron status). The 10th, 25th, 50th, 75th, and 90th centiles for men and women were 139, 146, $152,157,163$, and 123, 129, 135, 141, $146 \mathrm{~g} / \mathrm{l}$, respectively.

To confirm that these differences also existed in a community based population, we provide data from a random nutrition survey of 4636 New Zealand adults. ${ }^{2}$ From the survey population we selected all non-pregnant participants aged $20-45$ years with a ferritin concentration of 50-100 $\mu \mathrm{g} / \mathrm{l}$ and a normal concentration of $\mathrm{C}$ reactive protein (to exclude participants with anaemia due to chronic inflammatory conditions). The 10th, 25th, 50th, 75th, and 90th centiles for men and women were 140, 146, $150,157,160(\mathrm{n}=110)$ and $127,131,138$, 142, $147 \mathrm{~g} / \mathrm{l}(\mathrm{n}=252)$, respectively. These results confirm our conclusion that the distribution of haemoglobin concentrations is substantially lower in women than in men.

This analysis also shows that, depending on the choice of the lower limit of haemoglobin for men (usually 130-135 g/l), $25-50 \%$ of women would be incorrectly classified as anaemic if a male reference range was used. This would have a profound public health impact owing to indiscriminate diagnosis of poor iron status in women.

With respect to ferritin concentrations, we agree that marked sex differences in ferritin distributions in a "normal" population occur because the iron requirements of menstruating women are higher and intakes lower than their male counterparts, resulting in lower iron stores among women. ${ }^{3}$ For ferritin, the lower limit of the reference range is more difficult to extract from population studies and should perhaps instead be based on biological definitions of iron deficiency, which include depletion of bone marrow iron stores. The appropriate ferritin cut-off value to use for defining iron deficiency is under debate,,$^{3-5}$ but most would agree that sex specific cut-off points are inappropriate for ferritin when defining iron deficiency.

Ian M Morison haematologist

Southern Community Laboratories, Dunedin, New Zealand 9001 ian.morison@sclabs.co.nz

Elaine L Ferguson lecturer

Department of Human Nutrition, University of Otago, Dunedin, New Zealand 9005

1 Rushton DH, Dover R, Sainsbury AW, Norris MJ, Gilkes JJ Ramsay ID. Why should women have lower reference limits for haemoglobin and ferritin concentrations than men BMJ 2001;322:1355-7. (2 June.)

2 Russell D, Parnell W, Wilson N, Faed J, Ferguson E, Herbison P, et al. NZ Food: NZ People. Key results of the 1997 National Nutrition Survey. Wellington: Ministry of Health, New Zealand Government, 1999.

3 Looker AC, Dallman PR, Carroll MD, Gunter EW, Johnson CL. Prevalence of iron deficiency in the United States. CL. Prevalence of iron

4 Ferguson EL, Morison IM, Faed JM, Parnell WR, McKenzie J. Wilson NC, et al. Dietary iron intakes and biochemical iron status of 15-49 year old women in New Zealand: is iron status of 15-49 year old women in New Zealan

there a cause for concern? N Z Med J 2001;114:134-8.
5 Hallberg L, Hulten L, Lindstedt G, Lundberg PA, Mark A 5 Hallberg L, Hulten L, Lindstedt G, Lundberg PA, Mark A, adolescents. Pediatr Res 1993;34:680-7.

\section{Authors' reply}

EDITOR-Heath et al acknowledge that women should be iron replete. The potential benefits far outweigh the possible overload affecting a very small proportion in whom monitoring may be employed. ${ }^{2}$ They say that the study by Zhu and Haas was too short and that both tissue iron status and body iron stores were still improving simultaneously and had not yet reached a steady state. ${ }^{3}$ It was no surprise therefore to see an increase in the ferritin concentration and no rise in the haemoglobin concentration.

The contribution of Morison and Ferguson is welcomed, but their analysis of the data is flawed. They considered the female population to be iron replete, but the first data set was uncontrolled for the presence of chronic infection or inflammatory disease, and the subjects were unmatched for age or weight. In the second set, they chose a lower ferritin concentration than in the first. The

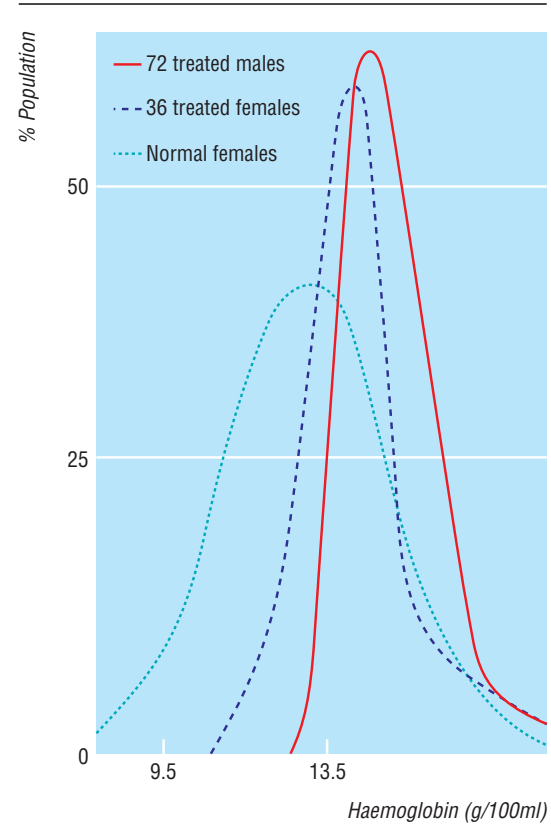

Frequency distribution of haemoglobin concentrations in response to iron treatment in anaemic men and women compared with "normal" women (reproduced with permission from Hobbs JR. Iron deficiency after partial gastrectomy. Gut 1961;2:141-9)

differences in haemoglobin concentrations were substantially lower, but not significant, in women compared with men. They agree that sex specific cut-off points for ferritin are inappropriate. In young people the median values only begin to diverge as menses exerts its effect: $4-6$ years $(28 \mu \mathrm{g} / 1$ men $v 27$ $\mu \mathrm{g} / \mathrm{l}$ women), 7-10 years, (29 $v 32), 11-14$ years (28 $v 28)$, and $15-18$ years (44 $v 23){ }^{4}$

We believe that a similar case exists for equality of lower haemoglobin values. Hobbs showed 40 years ago that the frequency distribution of haemoglobin concentration in response to iron supplementation in women paralleled that of men (figure). He concluded that the normal female range is not physiological and that iron should be given to all patients with a haemoglobin concentration below $13.6 \mathrm{~g} / 100 \mathrm{ml}(136 \mathrm{~g} / \mathrm{l})$.

Neither Heath et al nor Morison and Ferguson present any data to address the fact that no other mammals (including menstruating non-human primates) exhibit a sex difference for haemoglobin and red blood cell count (ferritin is not assessed in veterinary medicine). They also do not explain why these variables approximate in postmenopausal women and aged matched men, or why there are no significant differences in children. A healthy, iron replete, 30 year old woman has the same haem synthesis as one aged $60 .^{5}$ What biological evidence is there to employ different reference limits for premenopausal and postmenopausal women, other than widespread iron deficiency due to menses?

Our aim was to highlight the scale of the underestimation of iron deficiency in menstruating women and the deleterious effects 
on women's health. ${ }^{2}$ The practicalities of ensuring that women are iron replete are a separate issue.

Hugh Rushton honorary senior lecturer rushton@btinternet.com

Michael J Norris senior lecturer

School of Pharmacy and Biomedical Sciences,

University of Portsmouth, Portsmouth PO1 2DT

Robin Dover clinical research officer

Imperial Cancer Research Fund, London

WC2A 3PX

Anthony W Sainsbury senior veterinary officer Institute of Zoology, Zoological Society of London, London NW1 4RY

Jeremy J H Gilkes consultant dermatologist

Ian D Ramsay consultant endocrinologist

Lister Hospital, London SW1W 8RH

A longer version of this letter is available on bmj.com.

1 Dallman PR. Biochemical basis for the manifestations of iron deficiency. Ann Rev Nutr 1986;6:13-40.

2 Jackson HA, Carter K, Darke C, Guttridge MG, Ravine D, Hutton RD, et al. HFE mutations, iron deficiency and overload in 10,500 blood donors $B r$ Haematol 2001:114:474-4.

3 Zhu YI, Haas JD. Response of serum transferrin receptor to iron supplementation in iron-depleted, nonanemic to iron supplementation in iron-de
women. Am J Clin Nutr 1998;67:271-5.

4 Gregory J. Lowe S. National diet and nutrition survey: young people aged 4 to 18 years. London: Stationery Office, 2000.

5 Halliberg L, Hultén L, Gramatkovski E. Iron absorption from the whole diet in men: how effective is the regulation of iron absorption? J Clin Nutr 1997;66:347-56.

\section{Evaluating guidelines across primary care-secondary care interface}

\section{Methodological weaknesses and poor reporting undermine authors' conclusions}

EDITOR-Readers' ability to extract information from Morrison et al's study is impeded by errors in analysis and reporting. The trial evaluated clinical guidelines on the management of subfertility for doctors in general practice. The hope was that consequent improvements to procedure in primary care would affect processes in secondary care after referral, with more efficient management overall.

The subjects of the study were healthcare professionals, and the focus (the object of the intervention and the outcomes measured) was on their behaviour. All the results, however, are given as aggregated patient referrals, which does not respect the structure of the experiment.

Although one can compare case mix through aggregated patient characteristics (table 1), it is wrong to assess and report the effects of the intervention on this basis. ${ }^{2}$ The authors adjust for within practice correlation in their analysis, but at a level that is inappropriate. Two important consequences are the absence of information on variability between clinicians and inappropriate inflation of the sample size. Indeed, at a recent Medical Research Council meeting on cluster randomised trials it was acknowledged that using patients as the unit of analysis for trials in which the healthcare provider formed the natural subject is always incorrect.
Other concerns centre on the significant difference between the guideline and nonguideline groups in the number of appropriate investigations carried out in general practice, flagged as a "positive result" for the trial. Firstly, some confusion surrounds this statement. The paper refers to a "significantly higher mean number," with means given in table 2. Alongside the means, however, is an odds ratio with confidence interval and significance $(P=0.05)$. It is these latter figures that are given in the abstract, described as the binary outcome "all relevant investigations carried out," though now with $\mathrm{P}=0.025$ (presumably one sided)

Secondly, and fundamentally, this significant result stands in isolation among the outcomes measured. Naturally, it is efficient to measure several outcomes in a trial, summarising these with confidence intervals. However, if we ask essentially the same yes/no question several times in significance tests (here, whether guidelines modified doctors' behaviour) and get a single "yes" in reply, then multiplicity matters. The direct way through this is to pre-specify a single primary outcome to identify whether the trial is positive." As no such outcome is defined in the paper, the correct interpretation is that the trial is neutral. No post-hoc action can turn around this conclusion.

We frequently have just one opportunity to assess important questions of healthcare delivery in randomised controlled trials. These opportunities are wasted when studies are poorly designed and reported.

Nick Freemantle professor

Department of Primary Care and General Practice, University of Birmingham, Birmingham B15 2TT N.Freemantle@bham.ac.uk

John Wood principal statistician

GlaxoSmithKline, Harlow CM19 5AW

1 Morrion J, Camoll L, Twaddle S, Cameron I, Gimaw , Leyland A, et al. Pragmatic randomised controlled trial to evaluate guidelines across the primary care-secondar care interface. BMJ 2001;322:1282-4. (26 May.)

2 Wood J, Freemantle N. Choosing an appropriate unit of analysis in trials of interventions that attempt to influence practice. J Health Serv Res Policy 1999;4:44-88.

Freemantle N. Interpreting the results of secondary end points and subgroup analyses in clinical trials: should we lock the crazy aunt in the attic? BMI 2001;322-989-91. (21 April.)

\section{Authors' reply}

EDIToR-These authors believe that there are errors in the analysis and reporting of our study. We agree that patients should not be used as the unit of analysis for trials in which the healthcare provider forms the natural subject. For this reason our data were analysed as multilevel models with the multilevel modelling software MlwiN. ${ }^{1}$ As Freemantle and Wood have themselves pointed out, "multilevel models using appropriate statistical techniques can have some advantages over simple analyses at the appropriate unit of analysis.". Information about our use of multilevel modelling was given in the fuller version of our paper on the $B M$ J website but was not included in the shorter version in the paper journal.

In our view, it is inappropriate of these authors to cite anecdotal evidence from a meeting if that evidence is not currently available in any published form to other researchers. Readers are unable to assess the strength or weight of the assertion. The authors are correct to point out the error in the abstract. The $\mathrm{P}$ value of 0.05 reported in table 1 is the correct one, and we apologise for missing the error in the abstract when proofreading.

The message as to whether the guidelines modify doctors' behaviour is summed up precisely in table 1 and the text of the paper. The average number of investigations was significantly higher in intervention than control practices. Each of the five investigations was carried out more often in the intervention practices than the control practices, although the differences were not significant at the $5 \%$ level. It would take some sleight of hand before such results could be considered to point to the conclusion that the trial was neutral. Although we showed some modest change in doctors' behaviour, however, we were cautious about claiming that the overall intervention was worthwhile because we did not see the anticipated benefits in secondary care.

Jill Morrison professor

Department of General Practice, University of Glasgow, Glasgow G12 ORR

jmm4y@clinmed.gla.ac.uk

Alastair Leyland research scientist

MRC Social and Public Health Sciences Unit, University of Glasgow, Glasgow G12 8RZ

Jeremy Grimshaw professor

Health Services Research Unit, University of

Aberdeen, Aberdeen AB25 2ZD

1 Goldstein H. Multi-level statistical methods. London: Edward Arnold, 1995.

2 Wood J, Freemantle N. Choosing an appropriate unit of analysis in trials of interventions that attempt to influence practice. J Health Serv Res Policy 1999;4:44-88.

\section{Preventing suicides must remain a priority}

Editor-Davies et al are sceptical about the intention to reduce suicide set out in the national service framework on mental health, mainly because they regard suicide as rare. ${ }^{1}$ In fact, there are around 5000 suicides a year in England. This is more than the number of deaths in motor vehicle crashes and more than 10 times the number of deaths from the sudden infant death syndrome (cot deaths). Should we therefore give up on road safety? Should we stop advising parents about smoking or sleeping position? The number of cases may make it difficult for research to use suicide as an outcome, but that is a different issue.

Davies et al quote a finding from the national confidential inquiry into suicide and homicide by people with mental illness (one of my own projects). This says that few people under mental health care who commit suicide have been regarded by clinicians as being at high immediate risk in the days or weeks before death. They argue that improving risk assessment by staff would not therefore be worthwhile. This is not what the finding means. 
The inquiry figures show that to prevent suicide in clinical practice we need to strengthen services as a whole rather than focus only on the care of people known to be at high risk. This is particularly true in areas where services are weak-for example, in dealing with non-compliance or loss of contact, or in providing early follow up after discharge from hospital.

Suicide is the commonest cause of death in young men in England and the main cause of premature death in psychiatric patients. To reduce suicide we need a broadly based strategy, incorporating public health and clinical interventions, targeting key groups such as young men and restricting access to common methods of suicide such as overdose. A national suicide prevention strategy is now in preparation.

Louis Appleby national director for mental health, Department of Health

School of Psychiatry and Behavioural Sciences, University of Manchester, Manchester M20 8LR louis.appleby@man.ac.uk

1 Davies S, Naik PC, Lee AS. Depression, suicide, and the national service framework. BMJ 2001:322:1500-1. (23 June.)

\section{Euthanasia}

\section{Euthanasia already exists}

EDITOR-Emanuel misses the point in his editorial about euthanasia. ${ }^{1}$ The question is not "Should we debate whether to legalise euthanasia?" Euthanasia already happens, and is widely supported. ${ }^{2-5}$ The question is "Should we regulate existing practice using the Netherlands model?"

Jeremy Dearling staff nurse

Stroke Unit, Queen Elizabeth Hospital, King's Lynn PE30 4PT

jane.dearling@klshosp.anglox.nhs.net

1 Emanuel EJ. Euthanasia: where the Netherlands leads wil the world follow? BMJ 2001;322:1376-7. (9 June.)

2 Grassi L, Agostini M, Magnani K. Attitudes of Italian doc tors to euthanasia and assisted suicide for terminally il patients. Lancet 1999;354:1876-7.

3 Shah N, Warner J, Blizard B, King M. National survey of UK psychiatrists' attitudes to euthanasia. Lance 1998;352,9137:1360.

4 Tijmstra TJ, Kempen GI, Ormel J. [End of life and termination of life: opinions of elderly persons with health problems.] Ned Tijdschr Geneeskd 1997;141:2444-8. (In Dutch.)

5 Ward BJ, Tate PA. Attitudes among NHS doctors to requests for euthanasia. BMJ 1994;308:1332-4.

Figures for "slow euthanasia" should be included in data on physician assisted suicide

EDITOR-Emanuel is mistaken in stating that "if the objective is to improve the quality of care at the end of life then the battle over legalising euthanasia is an emotionally charged irrelevance." In my view, physician assisted suicide and voluntary euthanasia are a matter of personal choice and human rights. Having these options is extremely important for many individuals (including, I suspect, many $B M$ J readers) and should not be lightly disregarded as a minority issue. Legalising them would make the prospect of palliative care more acceptable to many terminally ill patients.
It is essential, when considering physician assisted suicide and voluntary euthanasia, to discuss the practice of "terminal sedation" or "slow euthanasia," which is knowingly performed in hospitals, nursing homes, hospices, and private homes throughout the world. This is carried out under the doctrine loosely described as double effect, by which a doctor may lawfully give increasing doses of regular analgesic and sedative drugs that can hasten someone's death as long as the declared intention is to ease pain and suffering.

Of course, the key word here is "intention." Doctors may, without publicly declaring the true purpose of their action, respond to a terminally ill patient's request and speed up the dying process in this way. From surveys in the Netherlands, Australia, and Belgium we know that "the alleviation of pain and symptoms with opioids in doses with a potential life-shortening effect" caused $19 \%, 31 \%$, and $19 \%$ of all deaths in these countries respectively. ${ }^{2}$

If we acknowledge the existence of voluntary slow euthanasia then at least some of these deaths (perhaps at least a quarter, according to the Belgian figures) should have been added to the comparatively low figures for physician assisted suicide and voluntary euthanasia that Emanuel quotes.

Michael H K Irwin vice chairman, Voluntary Euthanasia Society

9 Waverleigh Road, Cranleigh, Surrey GU6 8BZ michael-hk.irwin@virgin.net

1 Emanuel EJ. Euthanasia: where the Netherlands leads will the world follow? BMJ 2001:322:1376-7. (9 June.)

2 Deliens L, Mortier F, Bilsen J, Cosyns M, Vander Stichele R, Deliens L, Mortier F, Bilsen J, Cosyns M, Vander Stichele R,
Vanoverloop J, et al. End-of-life decisions in medical pracVanoverloop J, et al. End-of-life decisions in medical prac-
tice in Flanders, Belgium: a nationwide survey. Lancet 2000;356:1806-11.

\section{Symphysiotomies are important option in developing world}

EdiTor-Payne mentions possible legal action by women who had a "barbaric" symphysiotomy in Ireland. ${ }^{1}$ Many symphysiotomies were done in Roman Catholic countries, because contraception was illegal, even for medical indications, and women might have many caesarean sections with all the inherent risks.

In poor areas of the world thousands of women die or are maimed for life because they cannot obtain a symphysiotomy. The money, staff, and political stability to give all women in need access to a caesarean section are often not available. A symphysiotomy needs far less training and can be done in clinics without doctors. Most indigenous gynaecologists stopped teaching symphysiotomies about 20 years ago, thinking that development would make them obsolete. Instead, health services for the poor have deteriorated.

A typical example is that of a woman of 17 going into labour in Mozambique. No delivery has occurred after 16 hours. Three scenarios are possible.

Scenario 1-She is transported to the local clinic, where nothing can be done. The midwife is not trained or authorised to do a symphysiotomy. Hours later a macerated baby is delivered. If the woman survives she will probably be abandoned: she leaks urine continuously, and her vagina is so scarred that it is $1.5 \mathrm{~cm}$ deep.

Scenario 2-Somehow, transport to the nearest hospital (in Zimbabwe) is found. On arrival she has a fever and severely infected liquor, but there is fetal heart action. The doctor organises a caesarean section. The baby dies three hours later of trauma and infection. The woman has a severe postoperative infection, which affects the uterine incision. If she has not become infertile she will try again to deliver at home (the dead baby, wound infection, and cost have not won her over to Western health care). The scar will rupture, and she will die. The doctor will never find out

Scenario 3-The doctor does a symphysiotomy 10 minutes after admission (no need for a nurse anaesthetist). This early intervention, possible because no uterus has to be closed and the baby comes out easily, saves the baby-or perhaps it still dies. The next time, though, she has a larger pelvis and no scar in the uterus, and she may deliver successfully.

I have never heard of anybody dying of a symphysiotomy, whereas outside private city hospitals caesarean sections have a mortality of $1 \%$ in Africa. Reading in the $B M J$ about barbaric symphysiotomies will increase political resistance to this operation. Training in symphysiotomy might work though, especially if the technique was improved; the operation might then become politically correct.

D A A Verkuyl head, obstetrics and gynaecology United Bulawayo Hospitals, PO Box 958, Bulawayo, Zimbabwe

dverkuyl@healthnet.zw

1 Payne G. Ireland orders inquiry into "barbaric" obstetric practices. BMJ 2001;322:1200. (19 May.)

\section{Prices of CD4 assays and viral load tests must be reduced for developing countries}

Editor-Wise has reported that GlaxoSmithKline is to cut the price of some drugs in developing countries. ${ }^{1}$ For over a decade antiretroviral treatment has been available to patients in the United States and Europe. Because of the extent of HIV infection in the developing world, however, the cost of these drugs was way beyond the reach of the government treasuries in the world's poorest countries. As a result there was the ethical dilemma of "patents before patients," of life for developed countries and death for developing countries.

After worldwide protests led by South Africa, pharmaceutical companies have now decided to lower their drug prices considerably-indeed, by as much as $90 \%$. This certainly was welcome news for us in the Caribbean. On the other hand, as the drugs are to be taken indefinitely some of us in developing countries may still have problems 
to afford them, even at that landmark reduction in prices.

But this is only part of the therapeutic dilemma. Certain infrastructures will have to be in place to make treatment more accessible and to ensure compliance with treatment: non-compliance may quickly lead to an increase in drug resistant viruses. Proper use of antiretroviral drugs requires laboratories capable of measuring viral loads and CD4 counts and, indeed, a convenient central laboratory for testing for drug resistance. Unfortunately, this is an equally unaffordable part of HIV treatment in developing countries. In the Caribbean the cost of measuring CD4 counts, for example, is $£ 100$ (\$150), and for viral loads it is $£ 80-£ 100$ (\$120-\$150) - per test.

Obviously, therefore, the largesse of the pharmaceutical companies will have to be similarly matched by the companies that make and market CD4 assays and viral load tests. This has to be addressed urgently, otherwise the risk of the spread of blood resistant viruses worldwide will be added to the futility of offering cheaper drugs to some of the poorer developing countries. The cost of treatment may differ between developed and developing countries, but the standard of treatment should not.

I call on all governments from developing countries-in fact, the entire international community - to address this problem as a matter of urgency.

Courtenay Bartholomew emeritus professor of

medicine

7 Queens Park East, Port of Spain, Trinidad,

West Indies

mrc@wow.ne

1 Wise J. Glaxo cuts drug prices for developing countries. BMJ 2001;322:1510. (23 June.)

\section{Free supply of knowledge is good for developing countries}

EDITOR-In some developing countries poor people used to get a free supply of food grains and milk products because of the munificence of philanthropists in the developed world. For many this was the only source of nutrition available. Some social scientists argued that such regular supply would discourage local initiatives: in the long term the free supply of foodstuffs might not be beneficial to the recipient country. This criticism does not, however, apply to the free supply of knowledge and health information.

The provision of free access to medical journals to people in developing countries, achieved with the support of five publishers, is laudable. It is an unexpected gift to the needy medical community in less developed countries and was inconceivable a few years ago.

Medical colleges in developing countries face enormous financial constraints. They exist on low budgets and cannot afford subscriptions to journals. I have visited major medical colleges in different parts of India. Priorities may differ, but funds for the library will be the first to be cut.
Improved access to the internet is one of the welcome developments all over India. Five years ago, visiting cards of even eminent doctors did not contain an email address. Now it is different. In highly literate states, such as Kerala, some patients obtain information from the internet before visiting their doctors. The medical community in developing countries will be grateful to the people and agencies that took the initiative to make the full articles in several journals freely accessible to the public.

\section{K S Parthasarathy}

Atomic Energy Regulatory Board, Bombay

(Mumbai), India

parthasarathy@aerb.gov.in

1 Kmietowicz Z. Deal allows developing countries free access to journals. BMJ 2001:323:65. (14 July.)

\section{Tobacco control policy is regarded as fascism in Japan}

EDITOR-Smoking rates among adults in Japan are among the highest in the world, at $52.8 \%$ in men and $13.4 \%$ in women in 1998 The Japanese government does not have an effective antismoking policy, and this has led to a steady increase in deaths caused by lung cancer and in smoking rates among younger women and children. ${ }^{1-3}$

Each local government has started to tackle tobacco topics individually. In June this year the government of Shiga prefecture held an open forum against tobacco, at which the branch manager of Japan Tobacco made a speech denouncing the tobacco control plan as fascism. Later the comment was carried on several major television networks and in newspapers without censure.

Mainichi, one of the main daily newspapers in Japan, recently criticised the stopsmoking policy of Itami City as fascism. ${ }^{4}$ The city government has announced that it wishes to lower smoking rates to zero by 2011. The newspaper article also denounced antismoking campaigns in both European countries and the United States for their hypersensitiveness to the tobacco issue, concluding that any antismoking policy will infringe adults' liberty to smoke.

Public recognition of the health risks of smoking is increasing, and these responses were surprising. But evidently some media, which exercise authority in Japan, are still obstacles to the control of diseases related to smoking. Countering these obstacles will be the key to a solution. ${ }^{5}$

Iwao Gohma research fellow

Immunobiology Vaccine Center, University of Alabama at Birmingham, Birmingham, AL 35294-2170, USA

iwao@uab.edu

\footnotetext{
1 Shibuya K. Change in mortality and years of life lost attributable to tobacco in Japan, 1985 and 1995. Asia Pac J Public Health 1999;11:65-70.

2 Sone T. Tobacco-related scenes in television dramas for young Japanese audiences. Tob Control 1999;8:350.

3 Honjo K, Kawachi I. Effects of market liberalisation on smoking in Japan. Tob Control 2000;9:193-200.

4 Takada S. Think about "the declaration breaking off with smoking" of Itami city. Mainichi 17 July 2001:4.

5 Davis RM. Moving tobacco control beyond "the tipping point." BMJ 2000;321:309-10.
}

\section{Revalidation and assessment: giving marks might help}

EDITOR-Once again the BMJ's letters pages are full of correspondence about professional revalidation and assessment. ${ }^{1}$ Fortunately, with a change of leadership in the General Medical Council and greater realism within government, the tide is turning from complex systems of assessment that assume that every doctor is a potential rotten apple until proved otherwise, towards systems that assume that all the apples are sound except for a small minority, who need to be detected.

A characteristic feature of the NHS is that all patients enter the system through general practitioners, and all general practitioners refer overwhelmingly to a small number of consultants. A further characteristic is that there is little mobility in the system. Thus every specialist soon gets a feel for the competence of each general practitioner in his field of expertise, and every general practitioner soon perceives the strengths and weaknesses of the hospital consultants to whom he or she refers. It would take about half an hour for every general practitioner in the country to give a mark out of ten to every consultant he or she has regular dealings with, and conversely for consultants to mark all the general practitioners who make regular referrals to them. Simply a mark, with no comments or subdivisions, because this would function as a crude screening tool.

It would be easy to spot gross outliers. Any bias because of personal animosity or lack of knowledge would be diluted out because of the numbers included. Doctors whose marks fell below, say, the third centile, could be approached confidentially without their accusers being identified. The aim would be a closer examination and remedial action wherever possible. The other $97 \%$ could get on with their work, following their chosen routes of personal and professional development. They would not be hindered by the threat of constant appraisal and the resentment that this always incurs.

Only anaesthetists and academics would fall outside this simple system. Perhaps they could be judged by their ability to send each other to sleep.

Richard Lehman general practitioner Hightown Surgery, Banbury OX16 9DB lehman@hightown1.demon.co.uk

1 Burrows P, Gravestock N, McKinley RK, Fraser RC, Baker dation of clinicians [letters]. BMJ 2001;322:1600. (30 June.)

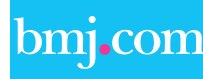

\section{Rapid responses}

Correspondence submitted electronically

is available on our website 